\title{
Accelerated discovery of proton-conducting perovskite oxide by capturing physicochemical fundamentals of hydration
}

Junji Hyodo $^{1}$, Kota Tsujikawa ${ }^{1,2}$, Motoki Shiga ${ }^{3,4}$, Yuji Okuyama ${ }^{5}$, and Yoshihiro Yamazaki ${ }^{1,2,6 *}$

1 INAMORI Frontier Research Center, Kyushu University, 744 Motooka, Fukuoka 819-0395, Japan

2 Department of Materials Science and Engineering, Kyushu University, 744 Motooka, Fukuoka 819-0395, Japan

3 Faculty of Engineering, Gifu University, 1-1 Yanagido, Gifu, 501-1193, Japan

4 Center for Advanced Intelligence Project, RIKEN, Nihonbashi 1-4-1 Nihonbashi, Chuo-ku, Tokyo, 103-0027, Japan

5 Research Center for Sustainable Energy \& Environmental Engineering, Faculty of Engineering, University of Miyazaki, 1-1 Gakuenkibanadai-nishi, Miyazaki 8892192, Japan

6 Kyushu University Platform of Inter-/Transdisciplinary Energy Research (Q-PIT), Kyushu University, 744 Motooka, Fukuoka 819-0395, Japan

* corresponding author: yamazaki.yoshihiro.105@m.kyushu-u.ac.jp 


\section{Experimental and Computational Sections}

\section{Sample Preparation}

22 acceptor-doped perovskite oxides were synthesized using a chemical solution method $^{1}$ or solid-state reaction method. All were sintered into a pellet and crushed into a powder form for thermogravimetry measurements. All the materials prepared here except the $\mathrm{SrSn}_{0.8} \mathrm{ScO}_{3-\delta}$ given in Table 2 are listed in Table $\mathrm{S} 1$.

\section{Thermogravimetry Measurements}

The proton concentrations of perovskite oxides were determined using thermogravimetry analysis, TGA (STA449F3 Jupiter, NETZSCH), in the temperature range between 50 and $1200{ }^{\circ} \mathrm{C}$. The samples were first heated at 1000 or $1200{ }^{\circ} \mathrm{C}$ for 1 $\mathrm{h}$ in dry- $\mathrm{N}_{2}$, dry-Ar, or dry- $10 \% \mathrm{O}_{2}-\mathrm{Ar}$ to dehydrate the sample. The gas was then switched to a wet gas saturated to a water partial pressure of $0.019-0.023 \mathrm{~atm}$. at the same temperature, and then the temperature was lowered under the wet atmosphere. The proton concentration was determined assuming that the weight gain from the dehydrated condition resulted from the hydration reaction, $V_{\mathrm{O}} \ddot{*}+\mathrm{O}_{\mathrm{O}}^{\times}+\mathrm{H}_{2} \mathrm{O} \longleftrightarrow 2 \mathrm{OH}_{\mathrm{O}}^{\cdot}$. To eliminate the buoyancy effect, the measurements were corrected by a blank test.

\section{Training Dataset for Hydration}

The training dataset for hydration, composed of proton concentration, $C_{\mathrm{H}}$, temperature, $T$, water partial pressure, $p_{\mathrm{H}_{2} \mathrm{O}}$, sintering temperature, $T_{\text {sinter, }}$, and sintering time, $t_{\text {sinter, }}$ are provided in Data $\mathrm{S} 1$.

\section{Descriptors for Machine Learning}

The 80 descriptors used in the machine learning model are listed below. They include the atomic weight, $w$, atomic density, $\rho$, melting temperature, $T_{\mathrm{m}}$, first ionization energy, $E_{1 \mathrm{st}}$, electronegativity, $\chi$, ionic radius, $r$, of the composed elements, where the values are divided or subtracted from one another and averaged over the Asite, $\mathrm{B}$-site, and entire $\mathrm{ABO}_{3}$ compound.

1) Temperature, $T$

2) Water partial pressure, $p_{\mathrm{H} 2 \mathrm{O}}$

3) Sintering temperature, $T_{\text {sinter }}$

4) Sintering time, $t_{\text {sinter }}$

5) Product of descriptors 3 ) and 4)

6) Formula weight of perovskite oxides, $M_{\mathrm{w}}$

7) Tolerance factor

8) Weighted average of $w, \rho, T_{\mathrm{m}}, E_{1 \mathrm{st}}, \chi$ and $r$ of A-site elements with its fraction in the A-site

9) Weighted average of $w, \rho, T_{\mathrm{m}}, E_{1 \mathrm{st}}, \chi$ and $r$ of B-site elements with its fraction in the B-site

10) Weighted average of $w, \rho, T_{\mathrm{m}}, E_{1 \mathrm{st}}, \chi$ and $r$ of dopant elements with its composition in perovskite

11) Weighted average of $w, \rho, T_{\mathrm{m}}, E_{1 \mathrm{st}}, \chi$ and $r$ of A-site host elements with its composition in perovskite 
12) Weighted average of $w, \rho, T_{\mathrm{m}}, E_{1 \mathrm{st}}, \chi$ and $r$ of B-site host elements with its composition in perovskite

13) Sum of descriptors 11) and 12) for each $w, \rho, T_{\mathrm{m}}, E_{1 \mathrm{st}}, \chi$ and $r$

14) Ratio of descriptors 8) to 9) for each $w, \rho, T_{\mathrm{m}}, E_{1 \mathrm{st}}, \chi$ and $r$

15) Ratio of descriptors 12) to 11) for each $w, \rho, T_{\mathrm{m}}, E_{1 \mathrm{st}}, \chi$ and $r$

16) Ratio of descriptors 10) to 11) for each $w, \rho, T_{\mathrm{m}}, E_{1 \mathrm{st}}, \chi$ and $r$

17) Ratio of descriptors 10) to12) for each $w, \rho, T_{\mathrm{m}}, E_{1 \mathrm{st}}, \chi$ and $r$

18) Ratio of descriptors 10) to 13) for each $w, \rho, T_{\mathrm{m}}, E_{1 \mathrm{st}}, \chi$ and $r$

19) Chemical composition of A-site dopant

20) Chemical composition of B-site dopant

21) Sum of descriptors 19) and 20)

22) Chemical composition of A-site host element

23) Chemical composition of B-site host element

24) Sum of descriptors 22) and 23)

25) $M_{\mathrm{w}}\left(r_{\mathrm{A}} r_{\mathrm{B}}\right)^{-1 / 2}$

The "dopant" was defined as an acceptor whose valence is lower than that of the host element. In the case of $\mathrm{La}_{0.9}^{3+} \mathrm{Sr}_{0.1}^{2+} \mathrm{Yb}_{0.5}^{3+} \mathrm{Y}_{0.5}^{3+} \mathrm{O}_{3-\delta}^{2-}$, No. 49 in Table S1, for example, only Sr is considered as the dopant. We assumed the valence of $\mathrm{Nd}(+2$ or +3$)$ and $\mathrm{Yb}(+2$ or +3 ) cations to be +3 . The Goldschmidt tolerance factor ${ }^{2}$ was defined as $\left(r_{\mathrm{A}}+r_{\mathrm{O}}\right) /\left\{\sqrt{2}\left(r_{\mathrm{B}}+r_{\mathrm{O}}\right)\right\}$, where $r_{\mathrm{A}}, r_{\mathrm{B}}$, and $r_{\mathrm{O}}$ denote the Shannon ionic radii ${ }^{3}$ of A-site cations, B-site cations, and oxygen ions, respectively. The descriptor 25) roughly expresses the theoretical density of perovskite oxides.

\section{Machine Learning Algorithms to Predict Hydration Behavior}

Four machine learning models, $k$-nearest neighbor regressor, kernel-ridge regressor, random forest regressor, and gradient boosting regressor, in the scikit-learn version 0.20.3 in Python, were used in this study. Changes of the parameters from the default are noted here. For the $k$-nearest neighbor regressor, the number of neighbors $k$ was optimized based on the prediction capability on cross-validation. For the kernelridge regressor, the radial basis function kernel was used. The hyperparameters of the kernel width and the weight of $\mathrm{L}_{2}$ regularization were optimized using cross-validation. For the random forest regressor and gradient boosting regressor, 500 trees (weak learners) were used. As preprocessing, training data whose value of $C_{\mathrm{H}} / C_{\text {dopant }}$ was less than 0.01 were eliminated. This procedure removed all the experimental results for $\mathrm{LaGa}_{0.8} \mathrm{Mg}_{0.2} \mathrm{O}_{3-\delta}$ and $\mathrm{La}_{0.9} \mathrm{Sr}_{0.1} \mathrm{AlO}_{3-\delta}$ (Nos. 64 and 65 in Table S1) from the training database. As post-processing, the predicted value of $C_{\mathrm{H}} / C_{\text {dopant }}$ was set as either 0 or 1 when it was outside the range of 0 to 1 . 
Table S1. Hydration enthalpies and entropies of 65 compounds determined by experiments and predicted by gradient boosting regression. These are provided as Data S2.

\begin{tabular}{|c|c|c|c|c|c|c|}
\hline No & Composition & $\begin{array}{c}\Delta H_{\text {exp. }} \\
\left(\mathrm{kJ} \mathrm{mol}^{-1}\right)\end{array}$ & $\begin{array}{c}\Delta S_{\text {exp. }} \\
\left(\mathrm{J} \mathrm{mol}^{-1} \mathrm{~K}^{-1}\right)\end{array}$ & $\begin{array}{c}\Delta H_{\text {pred. }} \\
\left(\mathrm{kJ} \mathrm{mol}^{-1}\right)\end{array}$ & $\begin{array}{c}\Delta S_{\text {pred. }} \\
\left(\mathrm{J} \mathrm{mol}^{-1} \mathrm{~K}^{-1}\right)\end{array}$ & Reference \\
\hline 1 & $\mathrm{BaZr}_{0.8} \mathrm{Y}_{0.2} \mathrm{O}_{3-\delta}$ & $-95 \pm 5$ & $-114 \pm 5$ & $-87 \pm 4$ & $-101 \pm 5$ & this work \\
\hline 2 & $\mathrm{BaZr}_{0.8} \mathrm{Y}_{0.2} \mathrm{O}_{3-\delta}$ & $-84 \pm 2$ & $-96 \pm 2$ & $-88 \pm 4$ & $-100 \pm 5$ & this work \\
\hline 3 & $\mathrm{BaZr}_{0.8} \mathrm{Y}_{0.2} \mathrm{O}_{3-\delta}$ & $-91 \pm 2$ & $-102 \pm 2$ & $-78 \pm 6$ & $-95 \pm 6$ & 4 \\
\hline 4 & $\mathrm{BaZr}_{0.8} \mathrm{Y}_{0.2} \mathrm{O}_{3-\delta}$ & $-89 \pm 12$ & $-124 \pm 14$ & $-70 \pm 13$ & $-89 \pm 15$ & 5 \\
\hline 5 & $\mathrm{BaZr}_{0.9} \mathrm{Y}_{0.1} \mathrm{O}_{3-\delta}$ & $-78 \pm 1$ & $-88 \pm 1$ & $-100 \pm 6$ & $-116 \pm 6$ & 4 \\
\hline 6 & $\mathrm{BaZr}_{0.9} \mathrm{Y}_{0.1} \mathrm{O}_{3-\delta}$ & $-70 \pm 5$ & $-94 \pm 5$ & $-99 \pm 3$ & $-116 \pm 3$ & 6 \\
\hline 7 & $\mathrm{BaZr}_{0.9} \mathrm{Y}_{0.1} \mathrm{O}_{3-\delta}$ & $-76 \pm 6$ & $-98 \pm 7$ & $-99 \pm 3$ & $-111 \pm 3$ & 6 \\
\hline 8 & $\mathrm{BaZr}_{0.9} \mathrm{Y}_{0.1} \mathrm{O}_{3-\delta}$ & $-77 \pm 4$ & $-97 \pm 5$ & $-99 \pm 3$ & $-105 \pm 3$ & 6 \\
\hline 9 & $\mathrm{BaZr}_{0.9} \mathrm{Y}_{0.1} \mathrm{O}_{3-\delta}$ & $-81 \pm 3$ & $-100 \pm 3$ & $-99 \pm 3$ & $-99 \pm 3$ & 6 \\
\hline 10 & $\mathrm{BaZr}_{0.95} \mathrm{Y}_{0.05} \mathrm{O}_{3-\delta}$ & $-83 \pm 3$ & $-99 \pm 3$ & $-71 \pm 4$ & $-86 \pm 4$ & 4 \\
\hline 11 & $\mathrm{BaZr}_{0.98} \mathrm{Y}_{0.02} \mathrm{O}_{3-\delta}$ & $-75 \pm 6$ & $-94 \pm 7$ & $-61 \pm 5$ & $-88 \pm 5$ & 4 \\
\hline 12 & $\mathrm{BaZr}_{0.7} \mathrm{Y}_{0.3} \mathrm{O}_{3-\delta}$ & $-90 \pm 19$ & $-124 \pm 21$ & $-77 \pm 13$ & $-110 \pm 14$ & 5 \\
\hline 13 & $\mathrm{BaZr}_{0.6} \mathrm{Y}_{0.4} \mathrm{O}_{3-\delta}$ & $-85 \pm 10$ & $-113 \pm 11$ & $-86 \pm 10$ & $-114 \pm 11$ & 5 \\
\hline 14 & $\mathrm{BaZr}_{0.8} \mathrm{Sc}_{0.2} \mathrm{O}_{3-\delta}$ & $-100 \pm 3$ & $-111 \pm 3$ & $-102 \pm 4$ & $-116 \pm 4$ & this work \\
\hline 15 & $\mathrm{BaZr}_{0.8} \mathrm{Sc}_{0.2} \mathrm{O}_{3-\delta}$ & $-96 \pm 1$ & $-106 \pm 1$ & $-109 \pm 2$ & $-119 \pm 2$ & 7 \\
\hline 16 & $\mathrm{BaZr}_{0.6} \mathrm{Sc}_{0.4} \mathrm{O}_{3-\delta}$ & $-108 \pm 1$ & $-115 \pm 1$ & $-89 \pm 4$ & $-108 \pm 4$ & this work \\
\hline 17 & $\mathrm{BaZr}_{0.8} \mathrm{In}_{0.2} \mathrm{O}_{3-\delta}$ & $-71 \pm 2$ & $-101 \pm 3$ & $-53 \pm 4$ & $-80 \pm 4$ & this work \\
\hline 18 & $\mathrm{BaZr}_{0.8} \mathrm{In}_{0.2} \mathrm{O}_{3-\delta}$ & $-65 \pm 2$ & $-109 \pm 3$ & $-52 \pm 5$ & $-81 \pm 6$ & this work \\
\hline 19 & $\mathrm{BaZr}_{0.8} \mathrm{Gd}_{0.2} \mathrm{O}_{3-\delta}$ & $-58 \pm 3$ & $-86 \pm 3$ & $-99 \pm 6$ & $-120 \pm 6$ & 4 \\
\hline 20 & $\mathrm{BaZr}_{0.8} \mathrm{Er}_{0.2} \mathrm{O}_{3-\delta}$ & $-82 \pm 2$ & $-106 \pm 3$ & $-88 \pm 4$ & $-113 \pm 5$ & this work \\
\hline 21 & $\mathrm{BaZr}_{0.8} \mathrm{Lu}_{0.2} \mathrm{O}_{3-\delta}$ & $-99 \pm 1$ & $-112 \pm 2$ & $-61 \pm 1$ & $-84 \pm 2$ & this work \\
\hline 22 & $\mathrm{BaCe}_{0.2} \mathrm{Zr}_{0.6} \mathrm{Y}_{0.2} \mathrm{O}_{3-\delta}$ & $-119 \pm 5$ & $-123 \pm 5$ & $-109 \pm 6$ & $-122 \pm 6$ & this work \\
\hline 23 & $\mathrm{BaCe}_{0.4} \mathrm{Zr}_{0.4} \mathrm{Y}_{0.2} \mathrm{O}_{3-\delta}$ & $-119 \pm 2$ & $-132 \pm 2$ & $-109 \pm 7$ & $-113 \pm 7$ & this work \\
\hline 24 & $\mathrm{BaCe}_{0.6} \mathrm{Zr}_{0.2} \mathrm{Y}_{0.2} \mathrm{O}_{3-\delta}$ & $-124 \pm 3$ & $-126 \pm 3$ & $-126 \pm 5$ & $-125 \pm 5$ & this work \\
\hline 25 & $\mathrm{BaCe}_{0.8} \mathrm{Y}_{0.2} \mathrm{O}_{3-\delta}$ & $-112 \pm 9$ & $-110 \pm 9$ & $-72 \pm 6$ & $-83 \pm 7$ & this work \\
\hline 26 & $\mathrm{BaSn}_{0.75} \mathrm{Y}_{0.25} \mathrm{O}_{3-\delta}$ & $-101 \pm 26$ & $-168 \pm 33$ & $-78 \pm 6$ & $-118 \pm 7$ & 8 \\
\hline 27 & $\mathrm{BaSn}_{0.95} \mathrm{Y}_{0.05} \mathrm{O}_{3-\delta}$ & $-71 \pm 9$ & $-132 \pm 11$ & $-41 \pm 10$ & $-86 \pm 12$ & 8 \\
\hline 28 & $\mathrm{BaSn}_{0.625} \mathrm{Y}_{0.375} \mathrm{O}_{3-\delta}$ & $-86 \pm 9$ & $-130 \pm 11$ & $-77 \pm 3$ & $-114 \pm 4$ & 8 \\
\hline 29 & $\mathrm{BaSn}_{0.875} \mathrm{Gd}_{0.125} \mathrm{O}_{3-\delta}$ & $-61 \pm 5$ & $-102 \pm 6$ & $-59 \pm 2$ & $-105 \pm 3$ & 9 \\
\hline 30 & $\mathrm{BaSn}_{0.875} \mathrm{In}_{0.125} \mathrm{O}_{3-\delta}$ & $-65 \pm 9$ & $-120 \pm 10$ & $-67 \pm 6$ & $-109 \pm 7$ & 9 \\
\hline 31 & $\mathrm{BaSn}_{0.875} \mathrm{Sc}_{0.125} \mathrm{O}_{3-\delta}$ & $-83 \pm 4$ & $-121 \pm 5$ & $-64 \pm 2$ & $-108 \pm 2$ & 9 \\
\hline 32 & $\mathrm{BaSn}_{0.875} \mathrm{Y}_{0.125} \mathrm{O}_{3-\delta}$ & $-53 \pm 2$ & $-94 \pm 3$ & $-67 \pm 3$ & $-116 \pm 3$ & 8,9 \\
\hline
\end{tabular}


Table S1. Continued.

\begin{tabular}{|c|c|c|c|c|c|c|}
\hline No & Composition & $\begin{array}{c}\Delta H_{\text {exp. }} \\
\left(\mathrm{kJ} \mathrm{mol}^{-1}\right)\end{array}$ & $\begin{array}{c}\Delta S_{\text {exp. }} \\
\left(\mathrm{J} \mathrm{mol}^{-1} \mathrm{~K}^{-1}\right)\end{array}$ & $\begin{array}{c}\Delta H_{\text {pred. }} \\
\left(\mathrm{kJ} \mathrm{mol}^{-1}\right)\end{array}$ & $\begin{array}{c}\Delta S_{\text {pred. }} \\
\left(\mathrm{J} \mathrm{mol}^{-1} \mathrm{~K}^{-1}\right)\end{array}$ & Reference \\
\hline 33 & $\mathrm{CaZr}_{0.96} \mathrm{In}_{0.04} \mathrm{O}_{3-\delta}$ & $-18 \pm 7$ & $-61 \pm 8$ & $-50 \pm 10$ & $-99 \pm 11$ & this work \\
\hline 34 & $\mathrm{La}_{0.3} \mathrm{Ba}_{0.7} \mathrm{Yb}_{0.5} \mathrm{In}_{0.5} \mathrm{O}_{3-\delta}$ & $-64 \pm 21$ & $-121 \pm 39$ & $-62 \pm 18$ & $-117 \pm 33$ & 10 \\
\hline 35 & $\mathrm{La}_{0.5} \mathrm{Ba}_{0.5} \mathrm{Yb}_{0.5} \mathrm{In}_{0.5} \mathrm{O}_{3-\delta}$ & $-72 \pm 14$ & $-140 \pm 23$ & $-50 \pm 10$ & $-94 \pm 11$ & 10 \\
\hline 36 & $\mathrm{La}_{0.7} \mathrm{Ba}_{0.3} \mathrm{Yb}_{0.5} \mathrm{In}_{0.5} \mathrm{O}_{3-\delta}$ & $-64 \pm 3$ & $-111 \pm 3$ & $-52 \pm 10$ & $-98 \pm 10$ & 10 \\
\hline 37 & $\mathrm{La}_{0.9} \mathrm{Ba}_{0.1} \mathrm{Yb}_{0.5} \mathrm{In}_{0.5} \mathrm{O}_{3-\delta}$ & $-67 \pm 3$ & $-100 \pm 3$ & $-58 \pm 10$ & $-90 \pm 11$ & 10 \\
\hline 38 & $\mathrm{La}_{0.9} \mathrm{Ba}_{0.1} \mathrm{YbO}_{3-\delta}$ & $-11 \pm 4$ & $-30 \pm 5$ & $-10 \pm 2$ & $-55 \pm 2$ & 11 \\
\hline 39 & $\mathrm{La}_{0.9} \mathrm{Ca}_{0.1} \mathrm{YbO}_{3-\delta}$ & $-10 \pm 4$ & $-51 \pm 4$ & $-30 \pm 7$ & $-59 \pm 8$ & 11 \\
\hline 40 & $\mathrm{La}_{0.9} \mathrm{Mg}_{0.1} \mathrm{YbO}_{3-\delta}$ & 0 & -54 & $5 \pm 5$ & $-29 \pm 6$ & 11 \\
\hline 41 & $\mathrm{La}_{0.9} \mathrm{Sr}_{0.1} \mathrm{InO}_{3-\delta}$ & $-92 \pm 4$ & $-127 \pm 4$ & $-76 \pm 8$ & $-109 \pm 9$ & 12 \\
\hline 42 & $\mathrm{La}_{0.9} \mathrm{Sr}_{0.1} \mathrm{ScO}_{3-\delta}$ & $-81 \pm 9$ & $-104 \pm 10$ & $-50 \pm 6$ & $-83 \pm 7$ & 12 \\
\hline 43 & $\mathrm{La}_{0.9} \mathrm{Sr}_{0.1} \mathrm{Y}_{0.2} \mathrm{In}_{0.8} \mathrm{O}_{3-\delta}$ & $-99 \pm 10$ & $-127 \pm 11$ & $-67 \pm 11$ & $-95 \pm 11$ & this work \\
\hline 44 & $\mathrm{La}_{0.9} \mathrm{Sr}_{0.1} \mathrm{Y}_{0.5} \mathrm{In}_{0.5} \mathrm{O}_{3-\delta}$ & $-59 \pm 11$ & $-82 \pm 12$ & $-54 \pm 10$ & $-83 \pm 11$ & this work \\
\hline 45 & $\mathrm{La}_{0.9} \mathrm{Sr}_{0.1} \mathrm{Y}_{0.8} \mathrm{In}_{0.2} \mathrm{O}_{3-\delta}$ & $-13 \pm 6$ & $-45 \pm 7$ & $-15 \pm 5$ & $-49 \pm 5$ & this work \\
\hline 46 & $\mathrm{La}_{0.9} \mathrm{Sr}_{0.1} \mathrm{Yb}_{0.2} \mathrm{In}_{0.8} \mathrm{O}_{3-\delta}$ & $-104 \pm 8$ & $-136 \pm 9$ & $-85 \pm 6$ & $-117 \pm 7$ & 13 \\
\hline 47 & $\mathrm{La}_{0.9} \mathrm{Sr}_{0.1} \mathrm{Yb}_{0.2} \mathrm{Y}_{0.8} \mathrm{O}_{3-\delta}$ & 0 & -31 & $-10 \pm 6$ & $-48 \pm 7$ & 13 \\
\hline 48 & $\mathrm{La}_{0.9} \mathrm{Sr}_{0.1} \mathrm{Yb}_{0.5} \mathrm{In}_{0.5} \mathrm{O}_{3-\delta}$ & $-91 \pm 9$ & $-116 \pm 10$ & $-73 \pm 13$ & $-103 \pm 14$ & 13 \\
\hline 49 & $\mathrm{La}_{0.9} \mathrm{Sr}_{0.1} \mathrm{Yb}_{0.5} \mathrm{Y}_{0.5} \mathrm{O}_{3-\delta}$ & $-18 \pm 13$ & $-76 \pm 14$ & $-3 \pm 3$ & $-34 \pm 3$ & 13 \\
\hline 50 & $\mathrm{La}_{0.9} \mathrm{Sr}_{0.1} \mathrm{Yb}_{0.8} \mathrm{In}_{0.2} \mathrm{O}_{3-\delta}$ & $-43 \pm 11$ & $-64 \pm 13$ & $-34 \pm 4$ & $-61 \pm 5$ & 13 \\
\hline 51 & $\mathrm{La}_{0.9} \mathrm{Sr}_{0.1} \mathrm{Yb}_{0.8} \mathrm{Y}_{0.2} \mathrm{O}_{3-\delta}$ & $-3 \pm 2$ & $-33 \pm 2$ & $-8 \pm 4$ & $-58 \pm 5$ & 13 \\
\hline 52 & $\mathrm{La}_{0.9} \mathrm{Sr}_{0.1} \mathrm{YbO}_{3-\delta}$ & 0 & -33 & $-43 \pm 8$ & $-68 \pm 8$ & 11,12 \\
\hline 53 & $\mathrm{La}_{0.9} \mathrm{Sr}_{0.1} \mathrm{YO}_{3-\delta}$ & $-4 \pm 3$ & $-38 \pm 3$ & $-4 \pm 3$ & $-35 \pm 4$ & 12 \\
\hline 54 & $\mathrm{Nd}_{0.9} \mathrm{Sr}_{0.1} \mathrm{InO}_{3-\delta}$ & $-51 \pm 5$ & $-84 \pm 5$ & $-65 \pm 6$ & $-100 \pm 7$ & this work \\
\hline 55 & $\mathrm{Sm}_{0.9} \mathrm{Sr}_{0.1} \mathrm{InO}_{3-\delta}$ & $-50 \pm 4$ & $-84 \pm 4$ & $-32 \pm 7$ & $-74 \pm 8$ & this work \\
\hline 56 & $\mathrm{SrCe}_{0.2} \mathrm{Zr}_{0.7} \mathrm{Y}_{0.1} \mathrm{O}_{3-\delta}$ & $-151 \pm 26$ & $-178 \pm 29$ & $-89 \pm 10$ & $-105 \pm 11$ & 14 \\
\hline 57 & $\mathrm{SrCe}_{0.4} \mathrm{Zr}_{0.5} \mathrm{Y}_{0.1} \mathrm{O}_{3-\delta}$ & $-84 \pm 22$ & $-89 \pm 23$ & $-79 \pm 10$ & $-95 \pm 10$ & 14 \\
\hline 58 & $\mathrm{SrCe}_{0.6} \mathrm{Zr}_{0.3} \mathrm{Y}_{0.1} \mathrm{O}_{3-\delta}$ & $-48 \pm 16$ & $-57 \pm 17$ & $-52 \pm 11$ & $-69 \pm 12$ & 14 \\
\hline 59 & $\mathrm{SrCe}_{0.9} \mathrm{Y}_{0.1} \mathrm{O}_{3-\delta}$ & $-11 \pm 4$ & $-32 \pm 5$ & $-51 \pm 14$ & $-58 \pm 15$ & 14 \\
\hline 60 & $\mathrm{SrCe}_{0.9} \mathrm{Yb}_{0.1} \mathrm{O}_{3-\delta}$ & $-16 \pm 6$ & $-30 \pm 7$ & $-29 \pm 8$ & $-39 \pm 9$ & this work \\
\hline 61 & $\mathrm{SrCe}_{0.95} \mathrm{Yb}_{0.05} \mathrm{O}_{3-\delta}$ & $-18 \pm 9$ & $-15 \pm 10$ & $-19 \pm 11$ & $-23 \pm 12$ & this work \\
\hline 62 & $\mathrm{SrCe}_{0.98} \mathrm{Yb}_{0.02} \mathrm{O}_{3-\delta}$ & $-8 \pm 5$ & $-13 \pm 6$ & $-13 \pm 10$ & $-17 \pm 11$ & this work \\
\hline 63 & $\mathrm{SrZr}_{0.9} \mathrm{Y}_{0.1} \mathrm{O}_{3-\delta}$ & $-121 \pm 10$ & $-157 \pm 11$ & $-107 \pm 17$ & $-133 \pm 18$ & 14 \\
\hline 64 & $\mathrm{LaGa}_{0.8} \mathrm{Mg}_{0.2} \mathrm{O}_{3-\delta}$ & $-1.5 \pm 0.6$ & $-74 \pm 1$ & $\mathrm{n} / \mathrm{a}$ & $\mathrm{n} / \mathrm{a}$ & this work \\
\hline 65 & $\mathrm{La}_{0.9} \mathrm{Sr}_{0.1} \mathrm{AlO}_{3-\delta}$ & $-37 \pm 4$ & $-126 \pm 4$ & $\mathrm{n} / \mathrm{a}$ & $\mathrm{n} / \mathrm{a}$ & 12 \\
\hline
\end{tabular}

The hydration enthalpy and entropy were determined from the linearity of a van't Hoff plot of the equilibrium constants for hydration in Figure S5b in the temperature range between 500 and $900{ }^{\circ} \mathrm{C}$. 
Table S2. Structural parameters of $\mathrm{SrSn}_{0.8} \mathrm{Sc}_{0.2} \mathrm{O}_{3-\delta}$ at room temperature. The lattice constant, crystallite size, atomic position $x$ for the O-site, and atomic displacement factor, $B_{\text {eq }}$, were variables in the Rietveld refinement. The occupancies, $g$, were fixed in the nominal values.

\begin{tabular}{llllll}
\hline Atom & $g$ & $x$ & $y$ & $z$ & $B_{\mathrm{eq}} / \AA^{2}$ \\
\hline $\mathrm{Sr}$ & 1 & 0 & 0 & 0.25 & $0.82(2)$ \\
$\mathrm{Sn}$ & 0.8 & 0 & 0 & 0 & $0.08(2)$ \\
$\mathrm{Sc}$ & 0.2 & $=x(\mathrm{Sn})$ & $=y(\mathrm{Sn})$ & $=z(\mathrm{Sn})$ & $=B_{\mathrm{eq}}(\mathrm{Sn})$ \\
$\mathrm{O}$ & 1 & $0.4667(11)$ & 0.0 & 0.25 & $3.09(12)$
\end{tabular}

Space group: $R \overline{3} c, a=5.71475(4) \AA, c=13.9993(4) \AA, V=395.942(12) \AA^{3}$,

crystallite size: $211(4) \mathrm{nm}, R_{\mathrm{wp}}=9.29 \%, R_{\exp }=5.74 \%$, GOF $\left(=R_{\mathrm{wp}} / R_{\exp }\right): 1.62$. 


\begin{tabular}{|c|c|c|c|c|c|c|c|c|c|c|c|c|c|c|c|c|c|c|}
\hline \multicolumn{11}{|c|}{$\mathrm{AB}_{1-x}{ }_{x} \mathrm{O}_{3-\delta}$} & \multicolumn{8}{|c|}{$\begin{array}{r}8613 \text { compositions, } 78 \text { hosts } \\
(0.05 \leq x \leq 0.45,0.05 \text { step })\end{array}$} \\
\hline & 1 & 2 & 3 & 4 & 5 & 6 & 7 & 8 & 9 & 10 & 11 & 12 & 13 & 14 & 15 & 16 & 17 & 18 \\
\hline I & $\mathbf{H}$ & & & & & & & & & & & & & & & & & $\mathrm{He}$ \\
\hline II & Li & $\mathrm{Be}$ & & & & & & & & & & & B & C & $\mathbf{N}$ & 0 & $\mathbf{F}$ & $\mathrm{Ne}$ \\
\hline III & $\mathrm{Na}$ & $\mathrm{Mg}$ & & & & & & & & & & & Al & Si & $\mathbf{P}$ & $\mathbf{s}$ & $\mathrm{Cl}$ & $\mathrm{Ar}$ \\
\hline IV & $\mathrm{K}$ & $\mathrm{Ca}$ & Sc & $\mathrm{Ti}$ & $\mathbf{v}$ & $\mathrm{Cr}$ & $\mathrm{Mn}$ & $\mathrm{Fe}$ & Co & $\mathrm{Ni}$ & $\mathrm{Cu}$ & $\mathrm{Zn}$ & $\mathrm{Ga}$ & $\mathrm{Ge}$ & As & $\mathrm{Se}$ & $\mathrm{Br}$ & $\mathrm{Kr}$ \\
\hline $\mathrm{V}$ & $\mathbf{R b}$ & $\mathrm{Sr}$ & $Y$ & $\mathrm{Zr}$ & $\mathrm{Nb}$ & Mo & TC & $\mathbf{R u}$ & $\mathbf{R h}$ & $P d$ & $\mathrm{Ag}$ & $\mathrm{Cd}$ & In & Sn & $\mathrm{Sb}$ & $\mathrm{Te}$ & I & $\mathrm{Xe}$ \\
\hline VI & Cs & $\mathrm{Ba}$ & Ln & $\mathrm{Hf}$ & $\mathrm{Ta}$ & w & $\mathbf{R e}$ & Os & Ir & $\mathrm{Pt}$ & $\mathrm{Au}$ & $\mathrm{Hg}$ & TI & $\mathrm{Pb}$ & $\mathbf{B i}$ & Po & At & Rn \\
\hline & & & Ln & La & $\mathrm{Ce}$ & $\mathrm{Pr}$ & $\mathrm{Nd}$ & $\mathrm{Pm}$ & Sm & Eu & Gd & Tb & Dy & Ho & Er & $\mathrm{Tm}$ & $Y b$ & Lu \\
\hline
\end{tabular}

Figure S1. Choice of elements for 8,613 hypothetical $\mathrm{AB}_{1-x} \mathrm{~B}_{x}{ }_{x} \mathrm{O}_{3-\delta}$ perovskites in 78 hosts. The A, B, and $\mathrm{B}^{\prime}$ cations are highlighted in red, green, and yellow, respectively, where $0.05 \leq x \leq 0.45$ with an increment of 0.05 . The valence of the $\mathrm{B} 1$ cation is always smaller than that of the B cation to realize acceptor doping. 


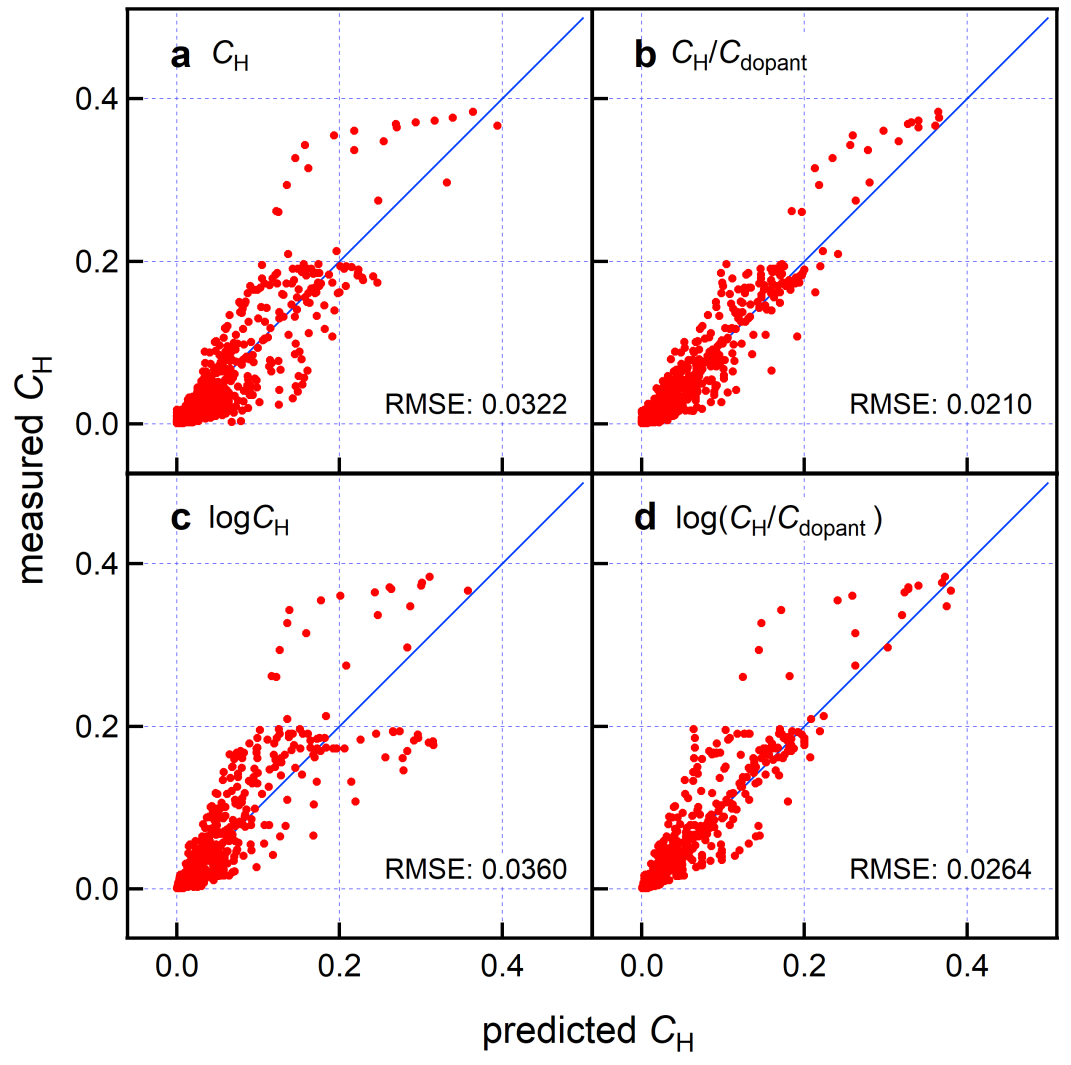

Figure S2. Impact of knowledge-based target variable engineering on prediction capability of proton concentration in gradient boosting regressor. (a) $C_{\mathrm{H}}$, (b) $C_{\mathrm{H}} / C_{\text {dopant }}$, (c) $\log C_{\mathrm{H}}$, and $\log \left(C_{\mathrm{H}} / C_{\text {dopant }}\right)$. The predicted values were computed based on leaveone-group-out cross-validation, in which all proton concentration data in the target chemical compounds were excluded from the training data for each prediction. 


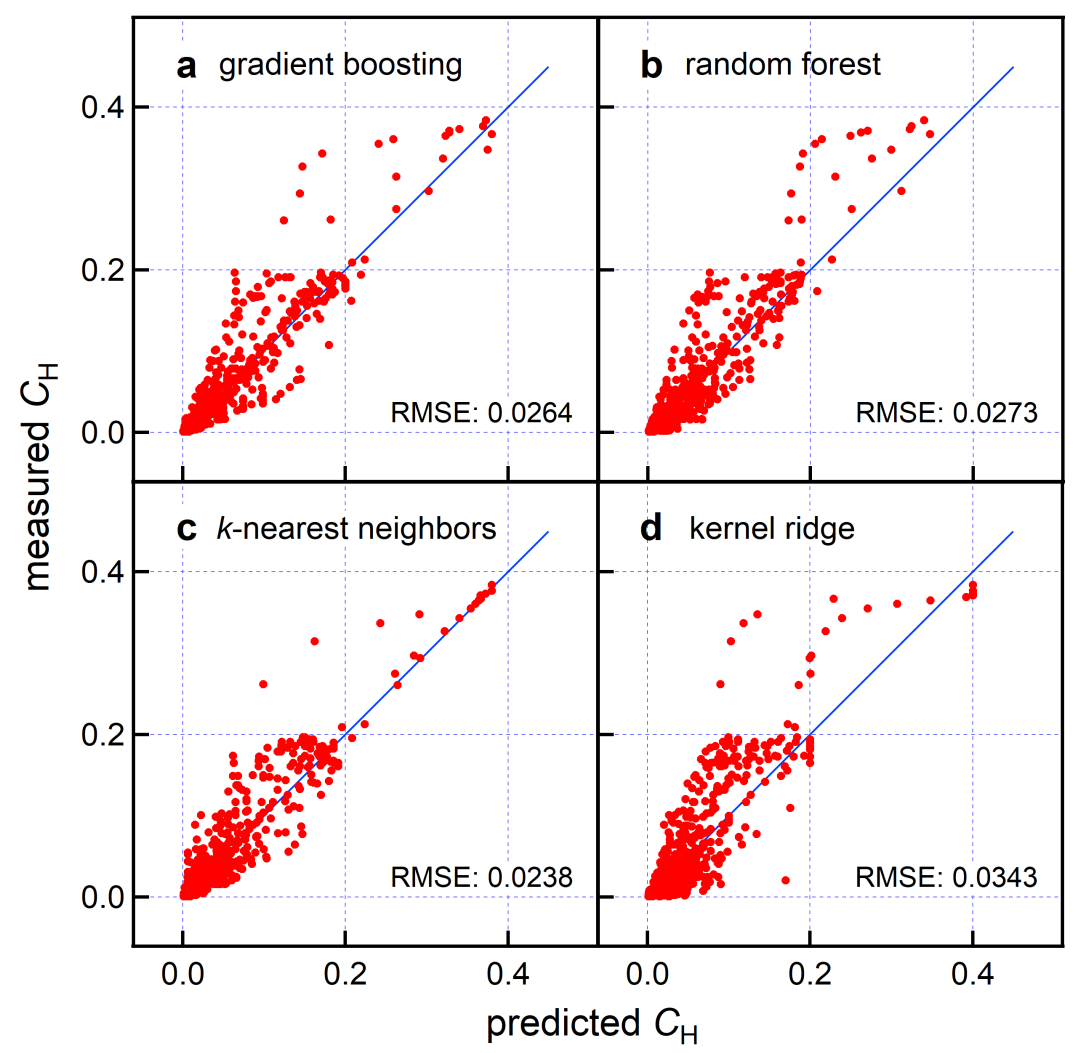

Figure S3. Prediction capability for proton concentration by (a) gradient boosting regressor, (b) random forest regressor, (c) $k$-nearest neighbors, and (d) Kernel-Ridge regressor. The predicted values were computed based on leave-one-group-out crossvalidation, in which all proton concentration data in the target chemical compounds were excluded from the training data for each prediction. The small RMSE for the $k$ nearest neighbors model in (c) suggests that the 80 descriptors used here are appropriate for describing the hydration behavior of perovskite materials because the prediction capability of $k$-nearest neighbors model precipitately drops when inappropriate descriptors are included in the model. 


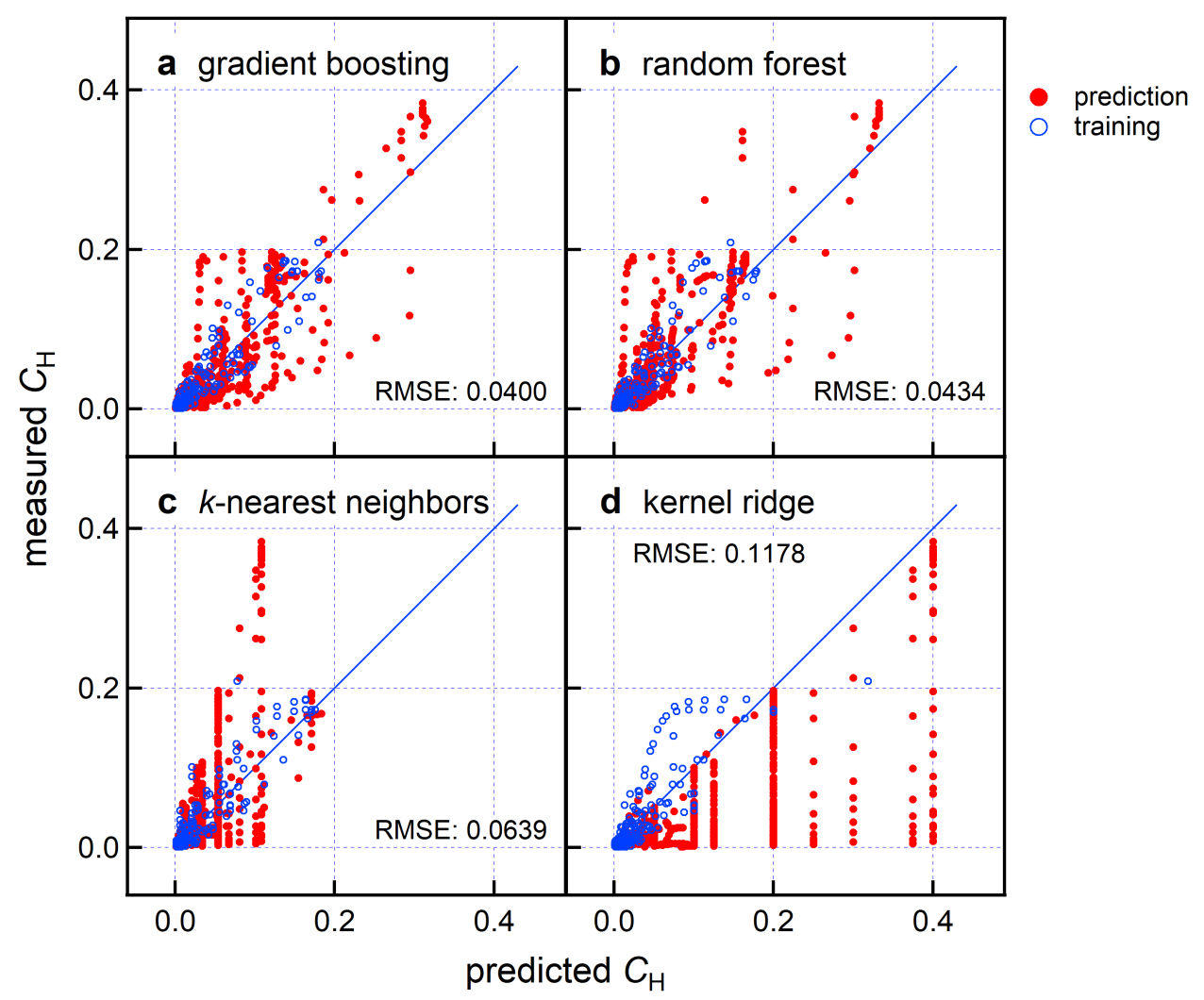

Figure S4. Comparison of four machine learning algorithms in leave-one-group-out cross-validation using two divided databases: (a) gradient boosting regressor, (b) random forest regressor, (c) $k$-nearest neighbors, and (d) kernel-ridge regressor. The datasets for perovskites that contain four cations (196 data points) were used as the training datasets, whereas those for the perovskites that contain three cations ( 512 data points) were used for the validation. The blue and red symbols show the results of crossvalidation for the training and validation datasets, respectively. The decision tree regressors using gradient boosting and random forest showed better prediction capability than the $k$-nearest neighbor and kernel-ridge regressor. We concluded that the gradient boosting regressor was the best method to predict the proton concentration in various compounds beyond the training datasets. 

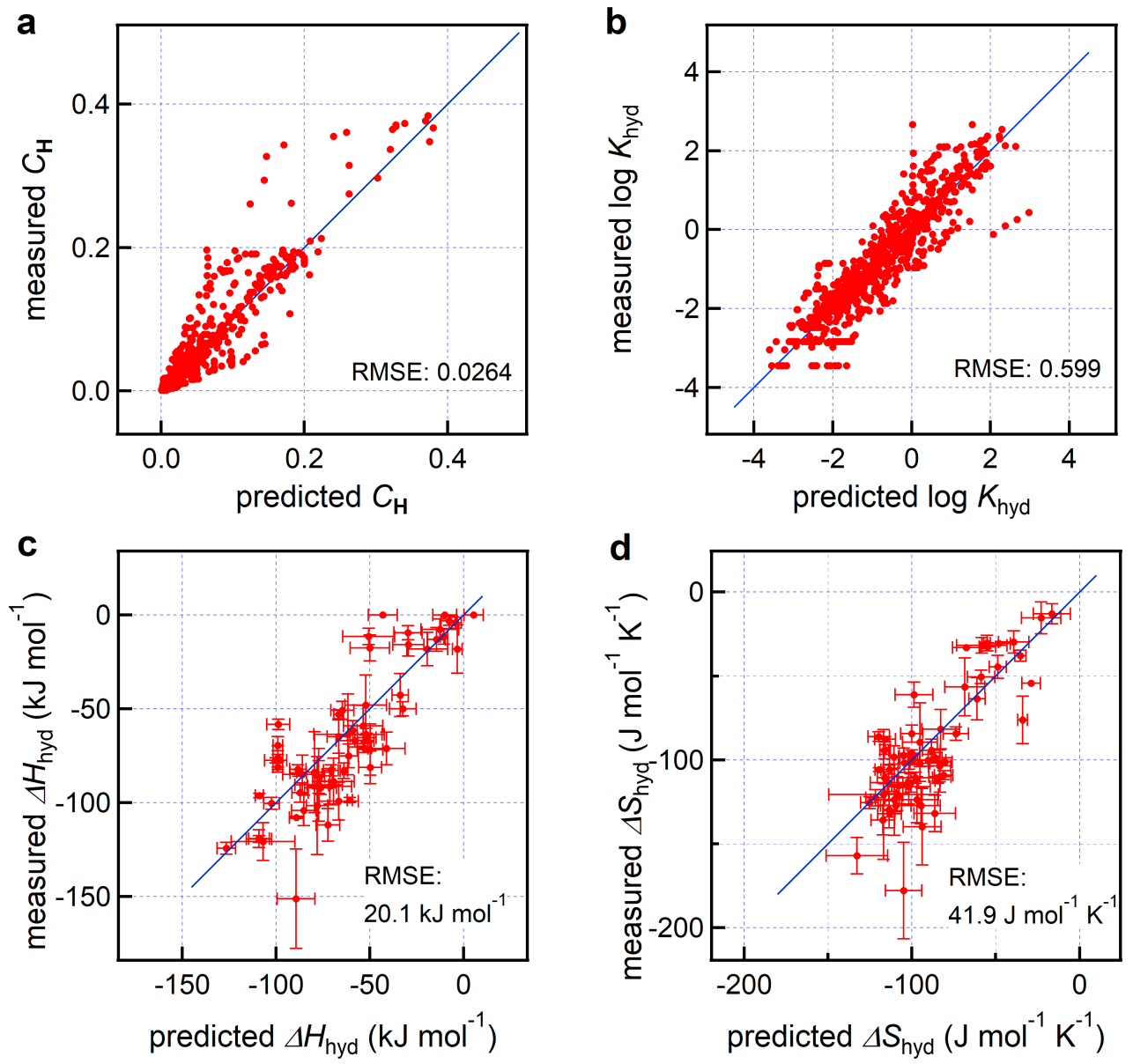

Figure S5. Predicting capability of gradient boosting regressors for proton concentration and hydration thermodynamics in perovskite oxides: (a) proton concentration, $C_{\mathrm{H}}$, (b) equilibrium constant of hydration, $K_{\text {hyd }}$, (c) hydration enthalpy, $\Delta H_{\text {hyd }}$, and (d) hydration entropy, $\Delta S_{\text {hyd }}$. The values of $K_{\text {hyd }}$ were calculated using $K_{\text {hyd }}=C_{\mathrm{H}}^{2} /\left(C_{V_{\mathrm{O}}} C_{\mathrm{O}} p_{\mathrm{H}_{2} \mathrm{O}}\right)$, where $C_{\mathrm{H}}, C_{V_{\mathrm{o}}}$, and $C_{\mathrm{O}}$ are the concentrations of protons, oxygen vacancies, and oxide ions, respectively, and $p_{\mathrm{H} 2 \mathrm{O}}$ is the water partial pressure. The hydration enthalpy and entropy were determined from the slope and intercepts of the van't Hoff plot in the temperature range between 500 and $900{ }^{\circ} \mathrm{C}$ assuming all the oxygen vacancies contribute to hydration. The error bars in (c) and (d) are determined from the uncertainty of linear curve fitting to the van't Hoff equation. 

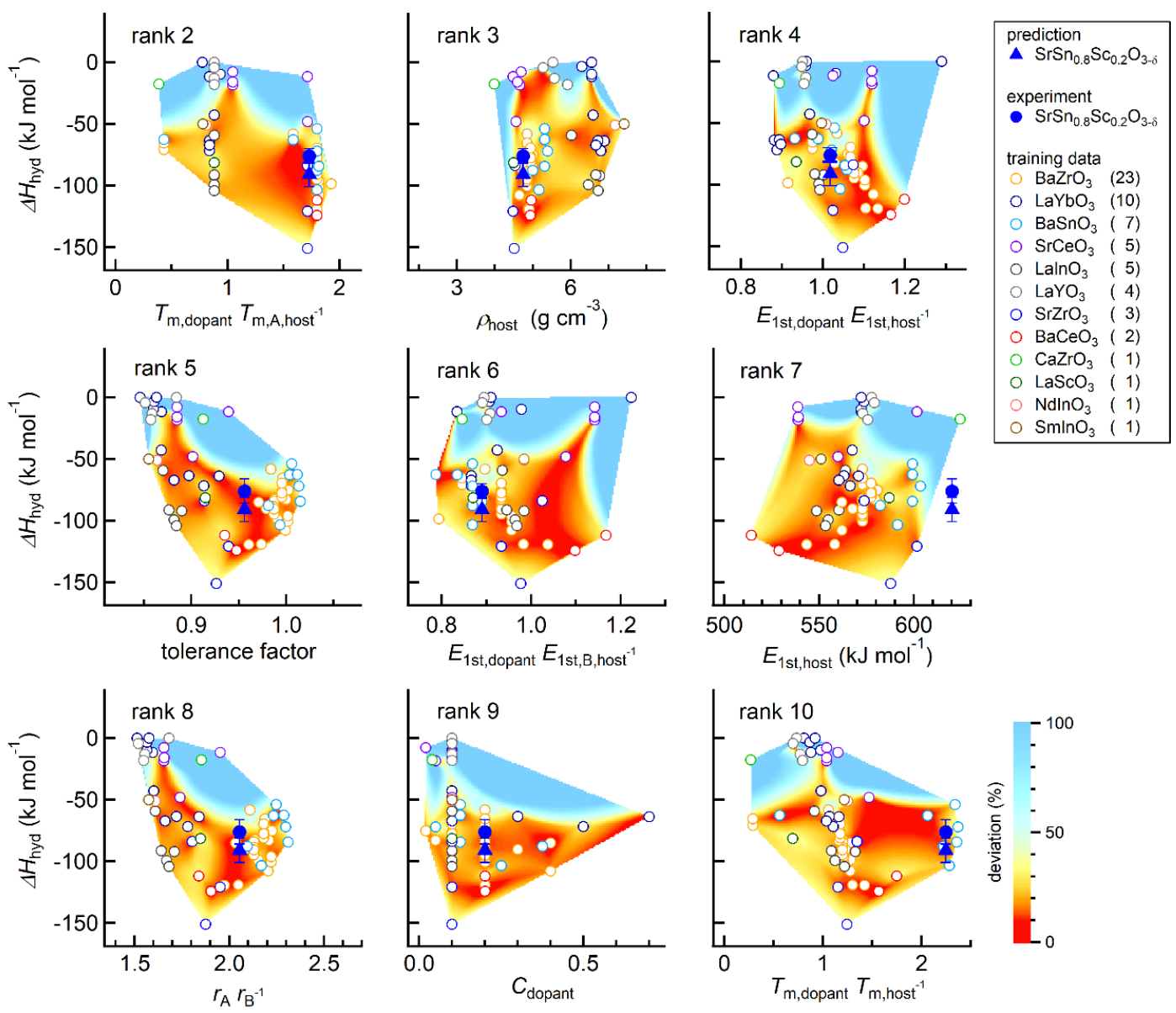

Figure S6. Structure-property maps for hydration in $2^{\text {nd }}-10^{\text {th }}$ ranked descriptor spaces. The descriptors are specified in Table 1 . The $2^{\text {nd }}$-ranked descriptor, $T_{\mathrm{m} . d o p a n t} / T_{\mathrm{m} . \text {.A.host }}$, roughly defines the type $3+/ 3+$ or $2+/ 4+$ perovskites, divided between the values 0.9 and 1.7. This is the highest and most influential among the 80 descriptors in feature importance of GBR except for temperature. The $3^{\text {rd }}$-ranked descriptor, the density of the host perovskite, basically shows similar information as the $2^{\text {nd }}$-ranked descriptor, where the $3+/ 3+$ and $2+/ 4+$ perovskites lie at about 7 and $5 \mathrm{gcm}^{-3}$, respectively. The boundary between $3+/ 3+$ and $2+/ 4+$ perovskites in the $3^{\text {rd }}$ descriptor space is vaguer than that in the $2^{\text {nd }}$-ranked descriptor space. The $4^{\text {th }}$ - and $6^{\text {th }}$-ranked descriptors reflect the type and concentration of the dopant. The $5^{\text {th }}$-ranked descriptor, the tolerance factor, and its related parameter, ranked $8^{\text {th }}$, show the symmetry of the structure. A value close to unity in the tolerance factor shows a cubic structure whereas a value less than 0.95 shows an orthorhombic structure at room temperature. The $7^{\text {th }}$-ranked descriptor shows the type of host compound. The $9^{\text {th }}$-ranked descriptor shows the concentration of the dopant. The $10^{\text {th }}$-ranked descriptor is sensitive to choices of dopant elements showing low melting temperature, such as In. 

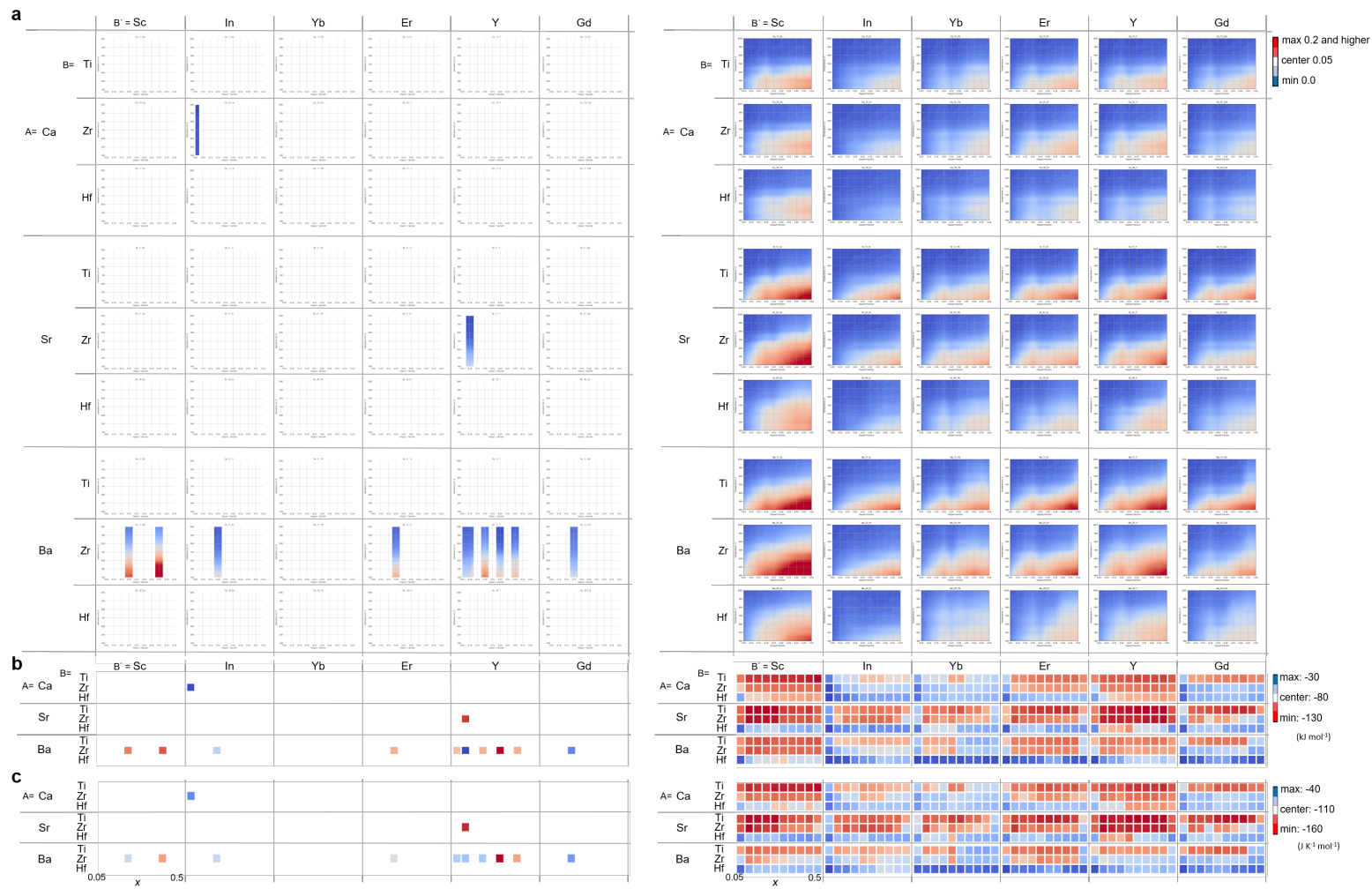

Figure S7. Structure-property maps for hydration in $540 \mathrm{AB}_{1-x} \mathrm{~B}_{x}{ }_{x} \mathrm{O}_{3}$ perovskites before (left) and after (right) machine learning prediction: a) proton concentration against chemical composition and temperature, b) hydration enthalpy, and c) hydration entropy. The input parameters of water partial pressure, sintering temperature, and sintering time for the gradient boosting regressors were fixed to $0.02 \mathrm{~atm}, 1600{ }^{\circ} \mathrm{C}$, and $24 \mathrm{~h}$, respectively. The host elements are $\mathrm{Ca}, \mathrm{Sr}$, and $\mathrm{Ba}$ for the A-site and $\mathrm{Ti}, \mathrm{Zr}$, and Hf for the B-sites. B-site dopants, B', are chosen from Sc, In, Yb, Er, Y, and Gd. The vertical axis in each box shows the temperature ranging from 400 to $1000{ }^{\circ} \mathrm{C}$, whereas the horizontal axis in each box shows dopant concentration, $x$, ranging from 0.05 to 0.5 with an increment of 0.05 . The actual composition of In-doped $\mathrm{CaZrO}_{3}$ oxide is $\mathrm{CaZr} 0.96 \mathrm{In}_{0.04} \mathrm{O}_{3-\delta}$. 


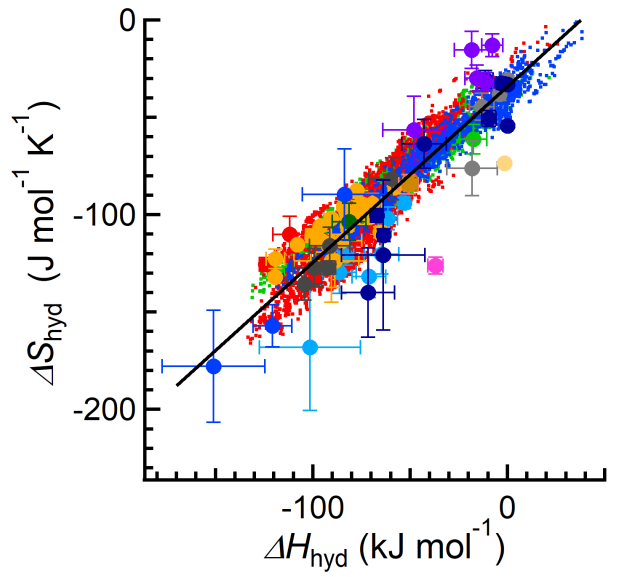

training data prediction

- $\mathrm{LaYbO}_{3}(10)$ 2+/4+ perovskite $(3105)$

- $\mathrm{LaYbO}_{3}(10): 3+13+$ perovskite (1728)

$\mathrm{SrCeO}_{3}(5)$

$\mathrm{LalnO}_{3}$ ( 5)

$\mathrm{LaYO}_{3}$ (4)

$\mathrm{SrZrO}_{3}$ ( (3)

- $\mathrm{BaCeO}_{3}(2)$

$\mathrm{CaZrO}_{3}(1)$

$\mathrm{LaAlO}_{3}(1)$

- $\mathrm{LaScO}_{3}(1)$

$\mathrm{LaGaO}_{3}(1)$

$\mathrm{NdlnO}_{3}(1)$

$\mathrm{SmInO}_{3}(1)$

Figure S8. Plot of predicted hydration entropies vs. hydration enthalpies for 8,613 hypothetical perovskites. The experimental data in Figure $2 \mathrm{~d}$ are shown as circles with error bars, whereas the predicted values for $1+/ 5+, 2+/ 4+$, and $3+/ 3+$ perovskites are shown as the green, red, and blue dots, respectively. 


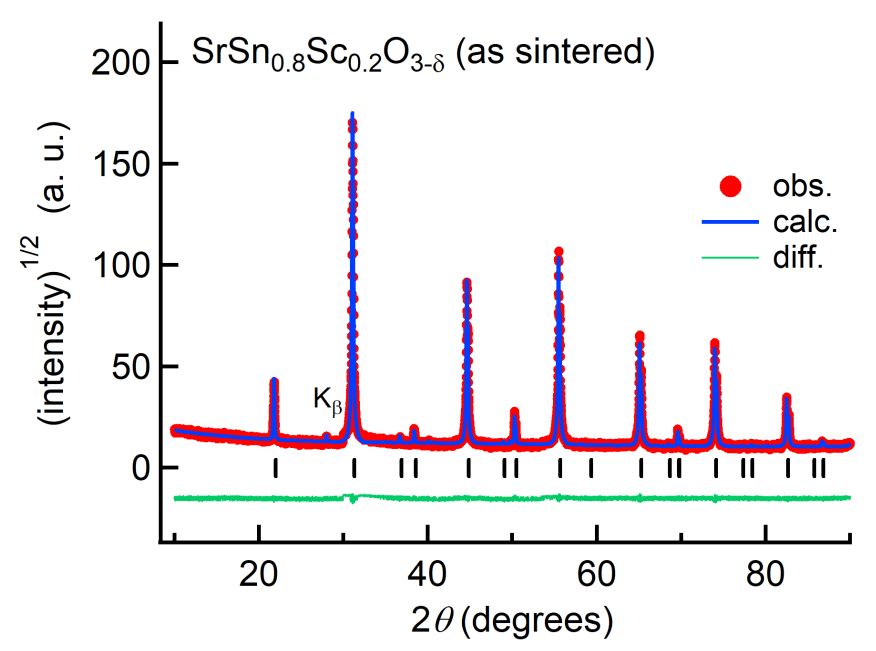

Figure S9. Powder XRD pattern for developed $\mathrm{SrSn}_{0.8} \mathrm{Sc}_{0.2} \mathrm{O}_{3-\delta}$. The red circles show the observed results and the blue and green lines show the patterns calculated by the Rietveld method and the differences between experimental and calculation results, respectively. The black marks are the Bragg positions for $\mathrm{Cu}-\mathrm{K}_{\alpha 1}$ radiation. The weak peak at $29.8^{\circ}$ is due to diffraction from $\mathrm{Cu}-\mathrm{K}_{\beta}$ radiation for the main peak. The measurement was performed after crushing the sintered pellet into a powder form. The refined structural parameters are summarized in Table S2. 
a

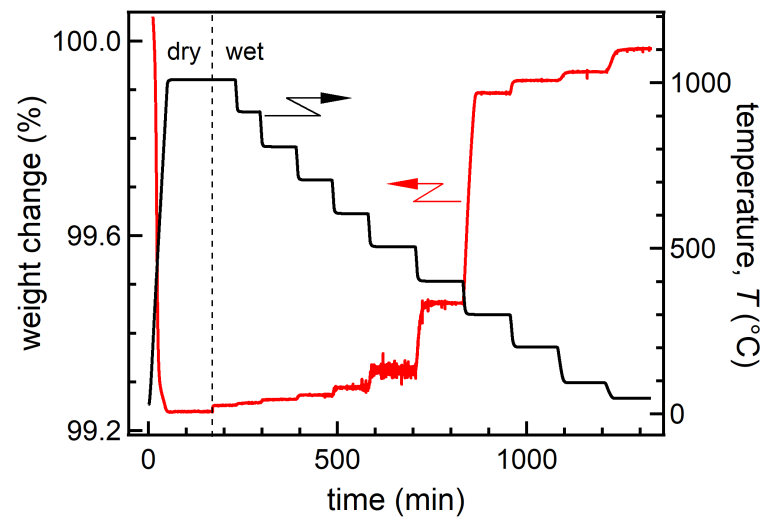

b $\quad T\left({ }^{\circ} \mathrm{C}\right)$

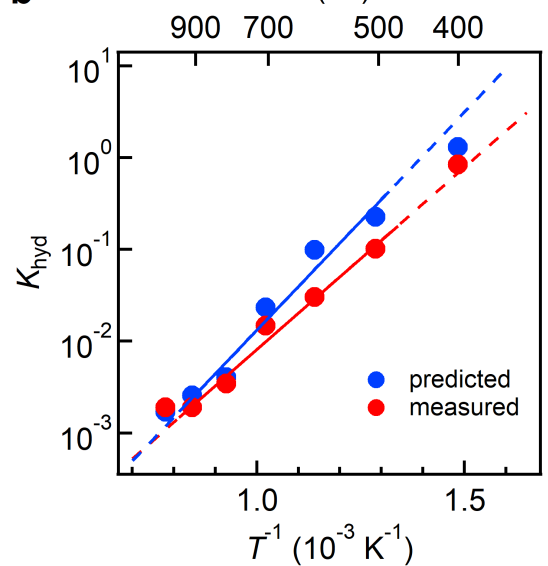

Figure S10. a) TGA raw data and b) Van't Hoff plots for $\mathrm{SrSn}_{0.8} \mathrm{Sc}_{0.2} \mathrm{O}_{3-\delta}$. The dashed line in (a) shows the time when the atmosphere was switched from dry to wet Ar. The obtained $\Delta H_{\text {hyd }}$ and $\Delta S_{\text {hyd }}$ in (b) are listed in Table 1 in the main text. 

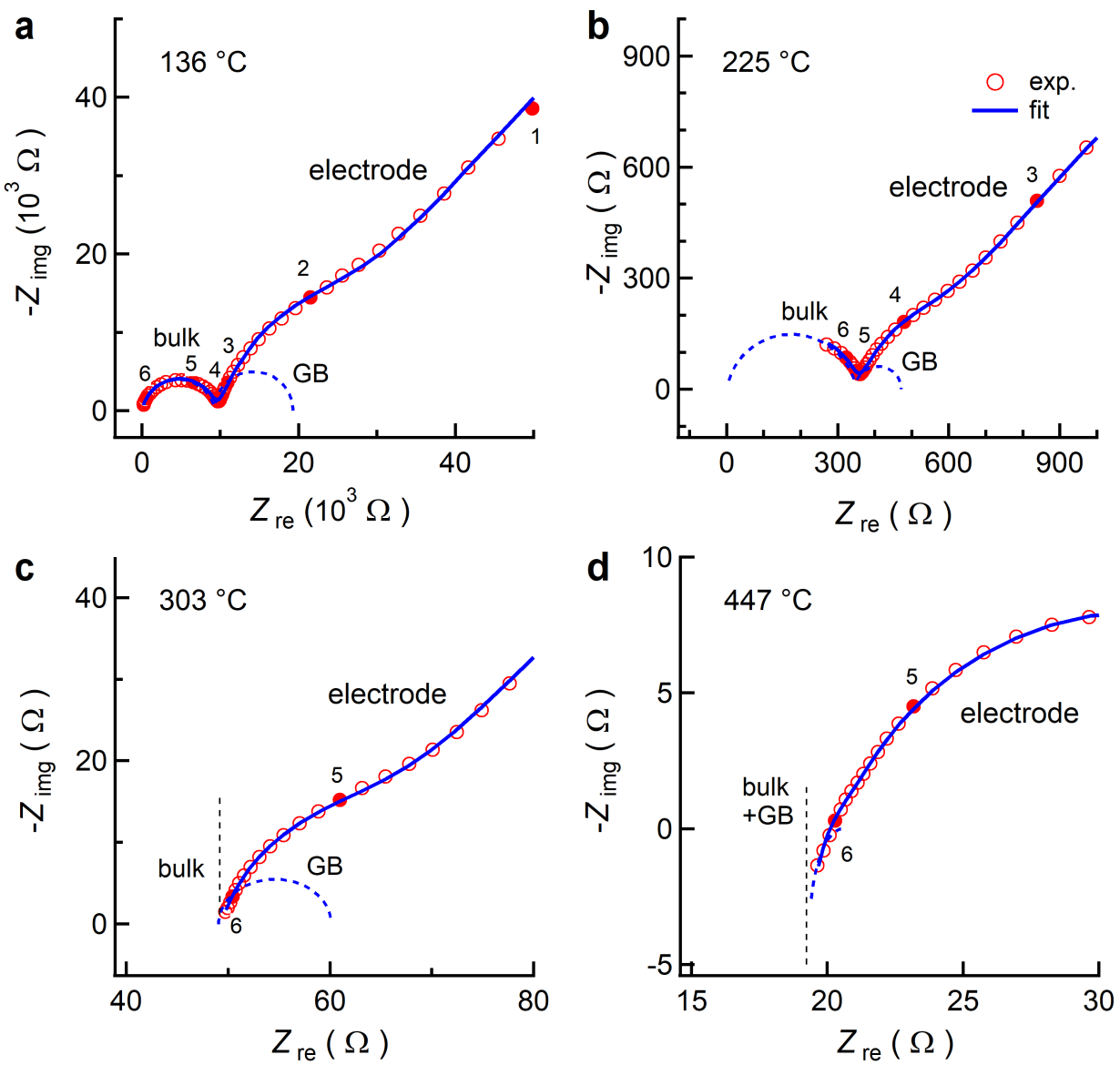

Figure S11. Nyquist plots for $\mathrm{SrSn}_{0.8} \mathrm{Sc}_{0.2} \mathrm{O}_{3-\delta}$ under a water partial pressure of 0.02 atm. The red circles and blue solid lines are the experimental and fitted results, respectively. The number beside each closed red circles corresponds to the exponent, $n$, of the base ten, $10^{n}$, in frequency. The dashed blue lines in a)-c) represent the semicircles assigned to the bulk or grain boundary based on the fitting parameters. The dashed black lines in c) and d) show the bulk and total resistance, respectively, obtained by fitting. 


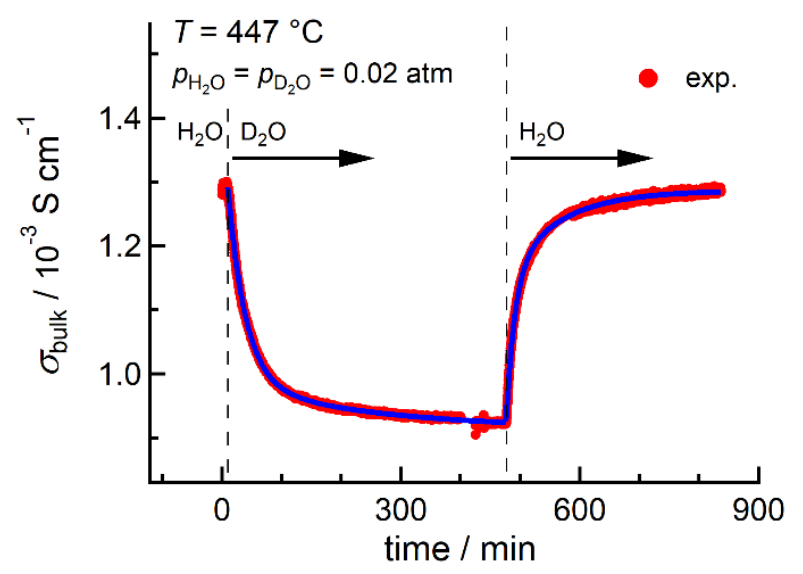

Figure S12. H/D isotope effect in bulk conductivity of $\mathrm{SrSn}_{0.8} \mathrm{Sc}_{0.2} \mathrm{O}_{3}-\delta$. The measurement was performed at $447^{\circ} \mathrm{C}$ in an Ar atmosphere under light- and heavywater partial pressures of $0.02 \mathrm{~atm}$. The red circles are the experimental results, whereas the blue line is a guide for the eye. A sudden change from $\mathrm{D}_{2} \mathrm{O}$ to $\mathrm{H}_{2} \mathrm{O}$ moisture while maintaining the partial pressure replaces deuterons with protons in the pellet. When the proton is the main carrier, an isotope effect with a factor of $1.41,\left(\mathrm{~m}_{\mathrm{D}} / \mathrm{m}_{\mathrm{H}}\right)^{1 / 2}$, is obtained because of the change in the vibrational frequency proportional to the square root of the mass, $\mathrm{m}_{i}$, of the carrier species $i$. The ratio of bulk conductivity under $\mathrm{H}_{2} \mathrm{O}$ to that under $\mathrm{D}_{2} \mathrm{O}$ was 1.41 , identical to the theoretical value. The proton conduction is also stable at $447^{\circ} \mathrm{C}$ for at least $800 \mathrm{~min}$. 


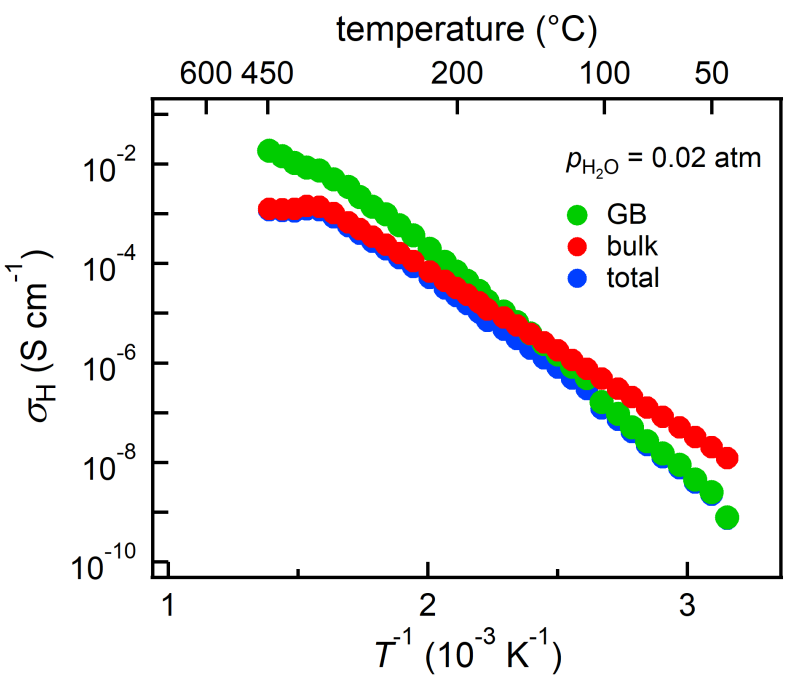

Figure S13. Grain boundary and total proton conductivities in $\mathrm{SrSn}_{0.8} \mathrm{Sc}_{0.2} \mathrm{O}_{3-\delta}$. The apparent grain boundary, bulk, and total conductivities are shown as green, red, and blue circles, respectively. 

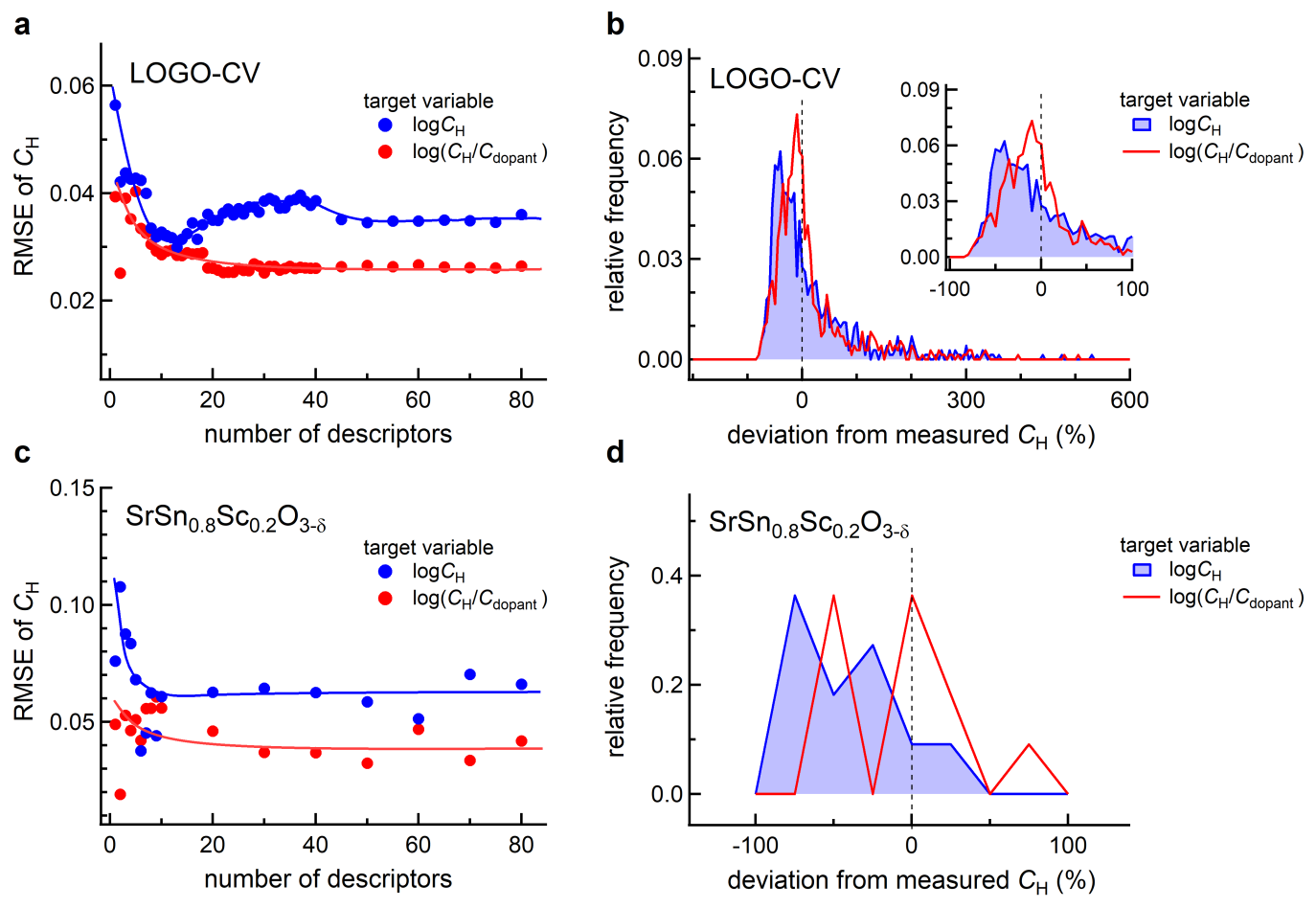

Figure S14. Impact of choice of target variable and descriptors on predicting capability of proton concentration against chemical composition and temperature. $a, b)$ Leaveone-group-out cross-validation (LOGO-CV) for 63 compounds and c, d) $\mathrm{SrSn}_{0.8} \mathrm{Sc}_{0.2} \mathrm{O}_{3}$ $-\delta$. The number of descriptors used in the prediction in a) and c) varied from one to eighty in order of ranking of feature importance of GBR for each target variable, while in b) and d) all 80 descriptors were used. The values on the $x$ and $y$ axes in b) and d) are normalized. The inset in b) shows a detail near $x=0$. The plots in a) and b) include 708 data points whereas those in c) and d) include 11 data points. Increasing the number of descriptors to 10-20 is effective in reducing the RMSE of $C_{\mathrm{H}}$ to a level close to the case of using all 80 descriptors and in improving the prediction capability. 


\section{REFERENCES}

1. Yamazaki, Y.; Hernandez-Sanchez, R.; Haile, S. M., High Total Proton Conductivity in Large-Grained Yttrium-Doped Barium Zirconate. Chem. Mater. 2009, 21 (13), 2755-2762.

2. Reaney, I. M.; Colla, E. L.; Setter, N., Dielectric and Structural Characteristics of Ba- and Sr-based Complex Perovskites as a Function of Tolerance Factor. Jpn. J. Appl. Phys. 1994, 33, 3984-3990.

3. Shannon, R. D., Revised Effective Ionic Radii and Systematic Studies of Interatomie Distances in Halides and Chaleogenides. Acta Cryst. 1976, A32, 751767.

4. Kreuer, K. D.; Adams, S.; Munch, W.; Fuchs, A.; Klock, U.; Maier, J., Proton conducting alkaline earth zirconates and titanates for high drain electrochemical applications. Solid State Ionics 2001, 145, 295-306.

5. Yamazaki, Y.; Babilo, P.; Haile, S. M., Defect Chemistry of Yttrium-Doped Barium Zirconate: A Thermodynamic Analysis of Water Uptake. Chem. Mater. 2008, 20, 6352-6357.

6. Schober, T.; Bohn, H. G., water vapor solubility and electrochemical characterization of high temperature proton conductor $\mathrm{BaZr}_{0.9} \mathrm{Y}_{0.1} \mathrm{O}_{2.95}$. Solid State Ionics 2000, 127, 351-360.

7. Hyodo, J.; Kitabayashi, K.; Hoshino, K.; Okuyama, Y.; Yamazaki, Y., Fast and Stable Proton Conduction in Heavily Scandium-Doped Polycrystalline Barium Zirconate at Intermediate Temperaturs. Adv. Energy Mater. 2020, 2000213.

8. Wang, Y.; Chesnaud, A.; Bevillon, E.; Dezanneau, G., Properties of Y-doped $\mathrm{BaSnO}_{3}$ proton conductors. Solid State Ionics 2012, 214, 45-55.

9. Wang, Y.; Chesnaud, A.; Bevillon, E.; Yang, J.; Dezanneau, G., Synthesis, structure and protonic conduction of $\mathrm{BaSn}_{0.875} \mathrm{M}_{0.125} \mathrm{O}_{3-\delta}(\mathrm{M}=\mathrm{Sc}, \mathrm{Y}$, In and $\mathrm{Gd})$. Int. J. Hydrogen Energy 2011, 36 (13), 7688-7695.

10. Okuyama, Y.; Yamaguchi, T.; Matsunaga, N.; Sakai, G., Proton Conduction and Incorporation into $\mathrm{La}_{1-x} \mathrm{Ba}_{x} \mathrm{Yb}_{0.5} \mathrm{In}_{0.5} \mathrm{O}_{3-\delta}$. Mater. Trans. 2018, 59 (1), 14-18.

11. Okuyama, Y.; Kozai, T.; Sakai, T.; Matsuka, M.; Matsumoto, H., Proton transport properties of $\mathrm{La}_{0.9} \mathrm{M}_{0.1} \mathrm{YbO}_{3-\delta}(\mathrm{M}=\mathrm{Ba}, \mathrm{Sr}, \mathrm{Ca}, \mathrm{Mg})$. Electrochim. Acta 2013, 95, 54-59.

12. Okuyama, Y.; Kozai, T.; Ikeda, S.; Matsuka, M.; Sakai, T.; Matsumoto, H., Incorporation and conduction of proton in Sr-doped $\mathrm{LaMO}_{3}(\mathrm{M}=\mathrm{Al}, \mathrm{Sc}, \mathrm{In}, \mathrm{Yb}, \mathrm{Y})$. Electrochim. Acta 2014, 125, 443-449.

13. Okuyama, Y.; Ikeda, S.; Sakai, T.; Matsumoto, H., Incorporation of a proton into $\mathrm{La}_{0.9} \mathrm{Sr}_{0.1}\left(\mathrm{Yb}_{1-x} \mathrm{M}_{x}\right) \mathrm{O}_{3-\delta}(\mathrm{M}=\mathrm{Y}, \mathrm{In})$. Solid State Ionics 2014, 262, 865-869.

14. Okuyama, Y.; Isa, K.; Lee, Y. S.; Sakai, T.; Matsumoto, H., Incorporation and conduction of proton in $\mathrm{SrCe}_{0.9-x} \mathrm{Zr}_{x} \mathrm{Y}_{0.1} \mathrm{O}_{3-\delta}$. Solid State Ionics 2015, 275, 35-38. 